\title{
Neue Redaktion ÖGUM-Mitteilungen
}

Nach mehr als 10 Jahren redaktioneller Tätigkeit für die ÖGUM-Mitteilungen habe ich beschlossen mit meinem Ausscheiden aus dem Vorstand auch die Agenden der ÖGUM-Mitteilungen abzugeben. Es war mir immer wichtig, die Mitglieder aktuell über Entwicklungen und Themen aus dem Vorstand möglichst zeitnah zu informieren, und daher mein Entschluss, die „Fe- der“ an einen aktiven „Vorständler“ weiterzugeben.

Ab kommenden Jahr 2018 wird daher Hannes Gruber (Uni Innsbruck) meine Agenden übernehmen und ab Heft 1 mit neuen Ideen und Beiträgen uns Mitglieder weiterhin „uptodate“ halten.
Für diese Aufgabe wünsche ich ihm alles Gute und die Zusendung vieler externer Beiträge unserer Arbeitskreise oder Mitglieder.

Christian Kollmann 